\section{Safety of \\ Triamcinolone acetonide (TA)- assisted pars plana vitrectomy in macular hole surgery}

\begin{abstract}
Aim To evaluate whether Triamcinolone acetonide (TA)-assisted pars plana vitrectomy for visualisation of posterior hyaloid during macular hole surgery has any adverse effects on macular hole closure rate and intraocular pressure (IOP).

Methods Case series comparing outcomes and adverse effects in patients who had surgery for macular holes with ILM peel, with and without the use of TA-assisted vitrectomy. Results During the study period, 29 patients had vitrectomy for macular holes. In 18 patients (group 1), TA was used intraoperatively to facilitate visualisation of the posterior hyaloid and in 11 patients (group 2) no TA was used. There was no statistically significant difference in the macular hole closure rates and the improvement in visual acuity between the two groups. No long-term increase in IOP was recorded in any of the 29 patients. The total anatomical success rate in both groups was $85.6 \%$ and the average improvement in visual acuity in both groups was two Snellen lines.

Conclusions TA is safe and there is no contraindication for its use as an intraoperative aid to facilitate vitreous visualisation in macular hole surgery. Eye (2007) 21, 591-594. doi:10.1038/sj.eye.6702265; published online 3 February 2006
\end{abstract}

Keywords: Triamcinolone acetonide; pars plana vitrectomy; macular hole; macular hole surgery; Triamcinolone-assisted vitrectomy

\section{Introduction}

Triamcinolone acetonide (TA) was introduced as an aid to facilitate pars plana vitrectomy
G Kampougeris, R Cheema, R McPherson and

C Gorman

(PPV) by Peyman et al in the year 2000. ${ }^{1}$ The use of TA improves visibility of vitreous and posterior hyaloid, and therefore facilitates complete posterior hyaloid separation and removal, which is an important step in macular hole surgery. However, there are concerns that use of a corticosteroid, such as TA, may adversely influence macular hole closure and may have other adverse effects such as raised intraocular pressure (IOP).

On review of the literature, no clinical studies have reported the effects of TA-assisted vitrectomy in macular hole surgery. The aim of this interventional, comparative, retrospective study was to assess the safety of TA-assisted PPV and its effects on macular hole closure and IOP.

\section{Methods}

We conducted a retrospective study on a consecutive series of patients who had vitrectomy for idiopathic macular holes in the University Hospital of Wales during a period of 24 months, between January 2003 and December 2004. Patients were identified by theatre computer system, where each type of operation has a unique code number. All operations were performed by three experienced vitreoretinal surgeons with or without TA according to surgeon's preference (one surgeon used TA in all cases, another in half of his cases, and the last in none of his cases). Operations were carried out in an otherwise similar fashion. Patients had standard three port PPV. After core vitrectomy, in cases where TA was used, $0.1-0.2 \mathrm{ml}$ of TA aqueous suspension (Kenalog, $40 \mathrm{mg} / \mathrm{ml}$ ) was reconstituted straight from the vial and was injected into the vitreous cavity. The white TA
Vitreoretinal Service, Cardiff Eye Unit, University Hospital of Wales, Cardiff, UK

Correspondence: RA Cheema,

Cardiff Eye Unit, University Hospital of Wales, Cardiff CF14 4XW, UK Tel: + 44292074 2794; Fax: + 442920748300 .

E-mail:drrac@ doctors.net.uk

Received: 25 July 2005 Accepted in revised form: 5 December 2005 Published online: 3 February 2006 
suspension was dispersed into the vitreous with light movements of the lightpipe and the vitrector, becoming entrapped in hyaloid gel rendering remaining vitreous and especially the posterior hyaloid easily visible.

Creation of posterior vitreous detachment (if not already present) and complete removal of vitreous was carried out. Any residual TA was removed with aspiration and flute needle. All cases had internal limiting membrane (ILM) peel, assisted with $0.1 \mathrm{ml}$ of ICG $(0.1 \mathrm{mg} / \mathrm{ml}$ of BSS), which was injected over the posterior pole in the BSS-filled eye and immediately washed out with a flute needle. At the end of the operation, all patients had injection of an iso-expansile $\mathrm{C}_{3} \mathrm{~F}_{8}$ gas into the vitreous cavity and asked to maintain face down posturing for 50 min every hour for 5 days. Postoperative medication in all patients included chloramphenicol and prednisolone $1 \%$ drops four times daily for 4 weeks and also acetazolamide tablets $250 \mathrm{mg}$ twice daily for 2 days.

The primary outcomes of the study were comparison of anatomical closure of macular hole with and without TA use and also to record any adverse effects from its use. The anatomical success of the operation (macular hole closure) was defined by the operating surgeon on clinical examination at follow-up appointments, where a detailed clinical examination including visual acuity with and without correction and IOP measurement for every patient was carried out. Statistical analysis of the results was carried out with SPSS statistical software (version 12.0.1, Professional Statistics Release, Chicago, USA).

\section{Results}

A total of 29 patients (29 eyes) were included in the study. Of these patients 18 had TA-assisted vitrectomy and 11 were operated without the use of TA (groups 1 and 2, respectively). Table 1 shows demographic data of patients. Macular hole stage, duration, and initial visual acuity of the patients is also depicted in Table 1, which shows that both groups had similar characteristics preoperatively. Regarding anatomical closure of macular holes, three operations failed in group 1 (success rate $15 / 18,83.3 \%$ ) and one operation failed in group 2 (success rate $10 / 11,90.9 \%$ ). The difference in anatomical success rate between the two groups was not statistically significant ( $P=0.5$, Fisher's exact test). Mean improvement in visual acuity in group 1 was $0.36 \pm 0.54$ (mean $\pm \mathrm{SD}$ ) $\log \mathrm{MAR}$, whereas in group 2 it was $0.44 \pm 0.76 \log$ MAR. This difference is again not statistically significant ( $P=0.22$, Mann-Whitney test). These results are shown in Table 2. Taken together, all 29 patients, who had macular hole surgery with or without TA, had an average improvement in their visual acuity after the operation of $0.37 \pm 0.62 \log$ MAR. The difference between preoperative and postoperative visual acuities was statistically significant $(P=0.001$, Wilcoxon test).

The average follow-up time for both groups is also shown on Table 1. During this period, there were no patients with long-term increase of IOP. This IOP rise in the immediate postoperative period, if encountered was controlled with short-term medical treatment, and at the routine follow-up appointments (at 2 weeks and 2 months postoperatively) none of the operated eyes had IOP above $21 \mathrm{mmHg}$ or was receiving any anti-glaucoma medication.

\section{Discussion}

Complete removal of posterior hyaloid membrane is an important surgical goal in macular hole surgery. Owing

Table 1 : Clinical characteristics of the two groups of patients with macular hole surgery

\begin{tabular}{|c|c|c|c|}
\hline & $\begin{array}{c}\text { Group } 1 \\
\text { (triamcinolone used) }\end{array}$ & $\begin{array}{c}\text { Group } 2 \\
\text { (no triamcinolone) }\end{array}$ & \\
\hline Number of patients & 18 & 11 & \\
\hline Age, years: mean (range) & $73.2(59-87)$ & $69(60-78)$ & $P=0.37, \mathrm{CI}:-3.07$ to $-8, t$-test \\
\hline Sex (male/female) & $4 / 14$ & $2 / 9$ & $P=0.59$, Fisher's exact test \\
\hline $\begin{array}{l}\text { Estimated duration of macular hole, } \\
\text { months: mean (range) }\end{array}$ & $10.3(5-20)$ & $7.7(2-15)$ & $P=0.06, \mathrm{CI}:-0.17$ to $-8.6, t$-test \\
\hline \multicolumn{4}{|l|}{ Macular hole stage } \\
\hline Stage 2 & 1 & 0 & $P=0.82, \chi^{2}$ test \\
\hline Stage 3 & 13 & 8 & \\
\hline Stage 4 & 4 & 3 & \\
\hline Follow-up, months: mean (range) & $7.4(3-20)$ & $8.3(3-19)$ & \\
\hline $\begin{array}{l}\text { Preoperative visual acuity, } \\
\text { logMAR: mean } \pm \text { s.d. (range) }\end{array}$ & $1.03 \pm 0.38(0.6-2)$ & $0.96 \pm 0.39(0.6-2)$ & $P=0.53$, Mann-Whitney test \\
\hline
\end{tabular}


Table 2 Outcomes and statistical analysis between the two groups

\begin{tabular}{lccc}
\hline & $\begin{array}{c}\text { Group 1 } \\
\text { (triamcinolone used) }\end{array}$ & $\begin{array}{c}\text { Group 2 } \\
\text { (no triamcinolone used) }\end{array}$ & P =0.5, Fisher's exact test \\
\hline Macular hole closure rate & $83.3 \%(15 / 18)$ & $90.1 \%(10 / 11)$ & $P=0.22$, Mann-Whitney test \\
$\begin{array}{l}\text { Improvement in visual acuity postoperatively } \\
\text { (logMAR, mean } \pm \text { s.d.) }\end{array}$ & $0.36 \pm 0.54$ & $0.44 \pm 0.76$ & 16.3 \\
Mean IOP (mmHg) at 2 months postoperatively & 17.4 & $P=0.14, t$-test \\
\hline
\end{tabular}

to the transparency of vitreous, it can be difficult to visualise and completely separate posterior hyaloid during PPV. The use of intravitreal TA suspension greatly improves visualisation of vitreous, thus facilitating removal of posterior hyaloid and vitreous during PPV. As a consequence, use of TA as an intraoperative tool for visualisation of vitreous gel in various clinical situations has expanded as more experience is gained from its use. $^{2-5}$

Triamcinolone is a corticoid with no retinal toxicity in vitrectomised and nonvitrectomised eyes in dosage of 2 to $4 \mathrm{mg}^{6}{ }^{6}$ The use of TA in nonvitrectomised eyes has been associated with complications such as raised IOP, cataract, ${ }^{9}$ and endophthalmitis. ${ }^{10}$ Animal studies have suggested that intravitreal injection of corticosteroids exerts an anti-inflammatory effect, inhibits growth of fibroblasts, ${ }^{11}$ and stabilises the blood-ocular barrier. ${ }^{12}$ As macular hole closure involves formation of fibro-glial elements, ${ }^{13,14}$ any residual TA in the vitreous cavity following vitrectomy has potential of adversely influencing macular hole closure.

Although the number of patients in the two groups in this study was small and a source of potential bias, there was no difference in macular hole closure rates between the two groups. No patients in either of the study groups had elevated IOP beyond 2 weeks in the post-operative period that could be attributed to the hypertensive effect of TA. The improvement in visual acuity in both groups, which did not show statistical difference, reflected similar macular hole closure rates in both groups. These findings suggest that removal of TA during vitrectomy and rapid clearance ${ }^{15,16}$ may possibly reduce concentration of TA to negligible levels where therapeutic or adverse effects of the drug cannot occur.

In conclusion, this study did not show any evidence of adverse effects of TA, when used as an intraoperative tool for posterior hyaloid separation and vitrectomy during macular hole surgery. Although further studies with larger number of patients may be needed to confirm these results, there appears to be no contraindication for the use of this technique by those surgeons who feel that is beneficial.

\section{References}

1 Peyman GA, Cheema R, Conway MD, Fang T. Triamcinolone acetonide as an aid to visualization of the vitreous and the posterior hyaloid during pars plana vitrectomy. Retina 2000; 20: 554-555.

2 Furino C, Micelli Ferrari T, Boscia F, Cardascia N, Recchimurzo N, Sborgia C. Triamcinolone-assisted pars plana vitrectomy for proliferative vitreoretinopathy. Retina 2003; 23(6): 771-776.

3 Enaida H, Hata Y, Ueno A, Nakamura T, Hisatomi T, Miyazaki $\mathrm{M}$ et al. Possible benefits of triamcinolone-assisted pars plana vitrectomy for retinal diseases. Retina 2003; 23(6): 764-770.

4 Sonoda KH, Enaida H, Ueno A, Nakamura T, Kawano YI, Kubota $\mathrm{T}$ et al. Pars plana vitrectomy assisted by triamcinolone acetonide for refractory uveitis: a case series study. Br J Ophthalmol 2003; 87(8): 1010-1014.

5 Peyman GA, Moshfeghi DM. Intravitreal triamcinolone acetonide. Retina 2004; 24(3): 488-490.

6 McCuen II BW, Bessler M, Tano Y, Chandler D, Machemer R. The lack of toxicity of intravitreally administered triamcinolone acetonide. Am J Ophthalmol 1981; 91: 785-788.

7 Jonas JB, Degenring RF, Kreissig I, Akkoyun I, Kamppeter BA. Intraocular pressure elevation after intravitreal triamcinolone acetonide injection. Ophthalmology 2005; 112(4): 593-598.

8 Ozkiris A, Erkilic K. Complications of intravitreal injection of triamcinolone acetonide. Can J Ophthalmol 2005; 40(1): $63-68$.

9 Jonas JB, Degenring R, Vossmerbauemer U, Kamppeter B. Frequency of cataract surgery after intravitreal injection of high-dosage triamcinolone acetonide. Eur J Ophthalmol 2005; 15(4): 462-464.

10 Moshfeghi DM, Kaiser PK, Scott IU, Sears JE, Benz M, Sinesterra JP et al. Acute endophthalmitis following intravitreal triamcinolone acetonide injection. Am J Ophthalmol 2003; 136(5): 791-796.

11 Tano Y, Sugita G, Abrams G, Machemer R. Inhibition of intraocular proliferations with intravitreal corticosteroids. Am J Ophthalmol 1980; 89: 131-136.

12 Ando N, Sen HA, Berkowitz BA, Wilson CA, de Juan E Jr. Localization and quantitation of blood-retinal barrier breakdown in experimental proliferative vitreoretinopathy. Arch Ophthalmolol 1994; 112: 117-122.

13 Yamana T, Kita M, Ozaki S, Negi A, Honda Y. The process of closure of experimental retinal holes in rabbit eyes. Graefes Arch Clin Exp Ophthalmol 2000; 238(1): 81-87. 
14 Funata M, Wendel RT, de la Cruz Z, Green WR. Clinicopathologic study of bilateral macular holes treated with pars plana vitrectomy and gas tamponade. Retina 1992; 12(4): 289-298.

15 Beer PM, Bakri SJ, Singh RJ, Liu W, Peters GB 3rd, Miller M. Intraocular concentration and pharmacokinetics of triamcinolone acetonide after a single intravitreal injection. Ophthalmology 2003; 110: 681-686.

16 Mason III JO, Somaiya MD, Singh RJ. Intravitreal concentration and clearance of triamcinolone acetonide in nonvitrectomized human eyes. Retina 2004; 24: 900-904. 